\title{
Arthropods Associate with their Red Wood ant Host without Matching Nestmate Recognition Cues
}

\author{
Thomas Parmentier $^{1,2}$ (D) $\cdot$ Wouter Dekoninck ${ }^{2} \cdot$ Tom Wenseleers $^{1}$
}

Received: 19 April 2017 /Revised: 28 June 2017 / Accepted: 12 July 2017

(C) Springer Science+Business Media, LLC 2017

\begin{abstract}
Social insect colonies provide a valuable resource that attracts and offers shelter to a large community of arthropods. Previous research has suggested that many specialist parasites of social insects chemically mimic their host in order to evade aggression. In the present study, we carry out a systematic study to test how common such chemical deception is across a group of 22 arthropods that are associated with red wood ants (Formica rufa group). In contrast to the examples of chemical mimicry documented in some highly specialized parasites in previous studies, we find that most of the rather unspecialized red wood ant associates surveyed did not use mimicry of the cuticular hydrocarbon recognition cues to evade host detection. Instead, we found that myrmecophiles with lower cuticular hydrocarbon concentrations provoked less host aggression. Therefore, some myrmecophiles with low hydrocarbon concentrations appear to evade host detection via a strategy known as chemical insignificance. Others showed no chemical disguise at all and, instead, relied on behavioral adaptations such as particular defense or evasion tactics, in order to evade host aggression. Overall, this study indicates that unspecialized myrmecophiles do not require the matching of host recognition cues and advanced strategies of chemical mimicry, but can
\end{abstract}

Electronic supplementary material The online version of this article (doi:10.1007/s10886-017-0868-2) contains supplementary material, which is available to authorized users.

Thomas Parmentier

Thomas.Parmentier@kuleuven.be

1 Laboratory of Socioecology and Socioevolution, KU Leuven, Naamsestraat 59, B-3000 Leuven, Belgium

2 Entomology Department, Royal Belgian Institute of Natural Sciences, Vautierstraat 29, B-1000 Brussels, Belgium integrate in a hostile ant nest via either chemical insignificance or specific behavioral adaptations.

Keywords Ant guests · Aggression · Chemical mimicry · Inquilines $\cdot$ Myrmecophiles $\cdot$ Social parasitism

\section{Introduction}

Organisms throughout the animal and plant kingdom use a variety of chemical strategies to deceive other species. They produce signals that mask their true nature from the target species, thereby tricking them to believe they are mating partners, nestmates, harmless or even mutualistic (Wyatt 2012). Spectacular examples can be found in Mastophora bolas spiders that lure and prey on male moths by imitating the female moth sex pheromone (Eberhard 1977) or in the pitchers of carnivorous plants that release flowery odors to trap insects (Joel 1988). Chemical deception, however, has been most thoroughly explored in parasites of social insects (Lenoir et al. 2001; Akino 2008; van Zweden and D'Ettorre 2010). Previous studies have shown that many arthropods succeed in penetrating the heavily defended fortresses of various species of social insects and avoid being aggressed by matching the chemical profile of their social insect hosts (Nash and Boomsma 2008; van Zweden and d'Ettorre 2010). Such deception can occur by passively acquiring the host's cuticular hydrocarbons (CHCs) that are used in nestmate recognition ("chemical camouflage") or in some cases even by actively producing them ("chemical mimicry") (Nash and Boomsma 2008; van Zweden and d'Ettorre 2010). In the present paper, we will refer to both types of matching as chemical mimicry, because only few studies have conclusively demonstrated the mechanism by which the matching of the host profile is achieved (see Table 1). In some cases it has also been reported 
that the parasites release specific secretions that appease, repel or manipulate the host (Hölldobler and Wilson 1990; Thomas et al. 2002; Akino 2008). Another strategy used in some species is one of "chemical insignificance", whereby arthropods suppress the production of hydrocarbons used in nestmate recognition in order to escape detection (Lenoir et al. 2001; Witte et al. 2008; Lenoir et al. 2013) (Table 1). Lastly, in a strategy known as chemical transparency, it was suggested that some species can integrate in social insect colonies by suppressing the production of some specific key host recognition cues (Cervo et al. 2008; Martin et al. 2008a).

Animals living inside the nest of social insects are known as inquilines. The group of arthropod inquilines associated with social insects comprise parasitic social insects, here referred to as "social inquilines", and a wide variety of nonsocial arthropods (Kistner 1982; Hölldobler and Wilson 1990). Current data indicate that chemical mimicry is especially common among social inquilines that are phylogenetically related to their host (Nash and Boomsma 2008; Buschinger 2009) Surprisingly, complete chemical mimicry or mimicry of some specific key recognition cues has also been reported as an integration mechanism in most of the non-social inquiline arthropods that live inside social insect colonies and which are all very distantly related to their host. In fact, chemical mimicry has been claimed to occur in 50 out of 61 inquilines of which the CHC composition has been compared to that of their social insect host (reviewed in Table 1). Nevertheless, most of these studies are biased in the sense that they have focused mainly on highly specialized parasites. We define specialists as integrated species that closely interact with their host, have a narrow host distribution, may engage in regular grooming interactions with their host, solicit for food and are often treated as regular colony members (Hölldobler and Wilson 1990; Kronauer and Pierce 2011; Parker 2016). The majority of such species are obligate parasites that feed on brood, steal food or live as ectoparasites on the brood (Hölldobler and Wilson 1990). In many cases, these specialized arthropods also combine complex chemical adaptations with other specialized behavioral or morphological adaptations, e.g. in some cases allowing for acoustical mimicry (Hölldobler and Wilson 1990; Di Giulio et al. 2015; Parker 2016). The true incidence of chemical mimicry of species living in social insect nests, however, may well be lower than presumed as there is also a large group of unspecialized associates, whose cuticular hydrocarbon profiles have as yet hardly been investigated. Such unspecialized species are not accepted in the colony by being groomed, fed or transported in contrast to specialized symbionts (Kistner 1982; Hölldobler and Wilson 1990) and provoke aggression to a varying degree (Parmentier et al. 2016b). They typically have a broad host distribution and are very similar in morphology to free-living relatives (Parmentier et al. 2014) and tend to live as facultative parasites, scavenging in the nest (Parmentier et al. 2016a).

Red wood ants (RWAs) (Formica rufa group) support a very diverse community of obligately associated arthropods. These arthropods are typically unspecialized and feed on other myrmecophiles, prey remnants or brood (Parmentier et al. 2016a). Most RWA myrmecophiles live as inquilines inside the nest, whereas some live extranidally in the close vicinity of the nest (Parmentier et al. 2014). Besides obligate myrmecophiles, RWA nests also host a wide array of facultatively associated myrmecophiles. These species are not strictly associated with ants, but often occur inside RWA mounds (Parmentier et al. 2014). A large group of myrmecophiles associated with RWAs can also be found in nests of other ant species (Parmentier et al. 2014).

The aim of the present study was to carry out a systematic study of the chemical integration mechanisms or strategies that weakly specialized RWA-associated arthropods use to evade host aggression. In order to do so, we analyzed the $\mathrm{CHC}$ profiles of the ant associates and compared their similarity to those of their host workers as well as the total amount of CHCs produced per surface area of the cuticle. Our hypothesis was that chemical mimicry would manifest itself in a high similarity in cuticular profiles between the ant associates and their host, whereas a quantitatively and qualitatively low similarity might point towards chemical insignificance. Both strategies are expected to result in lower host aggression. CHC similarity and concentration were, therefore, linked with host aggression for the myrmecophile community. The effect of CHC similarity and concentration was controlled with other functional traits, including host specificity, brood predation tendency, level of nest integration, trophic role and body size, investigated in this or previous studies.

\section{Methods and Materials}

\section{Study System}

As a study system we used red wood ants (Formica rufa group) and their community of associated arthropods. In our study region (Northern Belgium and Northern France), three of the six species of the F. rufa group can be found: Formica rufa Linnaeus, 1761, Formica polyctena Förster,1850 and Formica pratensis Retzius, 1783 (Dekoninck et al. 2010). They tend to differ in ecological preferences and in colonial organization (Seifert 2007), but all sampled colonies occurred along forest edges, contained multiple queens, and had polydomous colonies that extended over multiple mounds in our study region. 


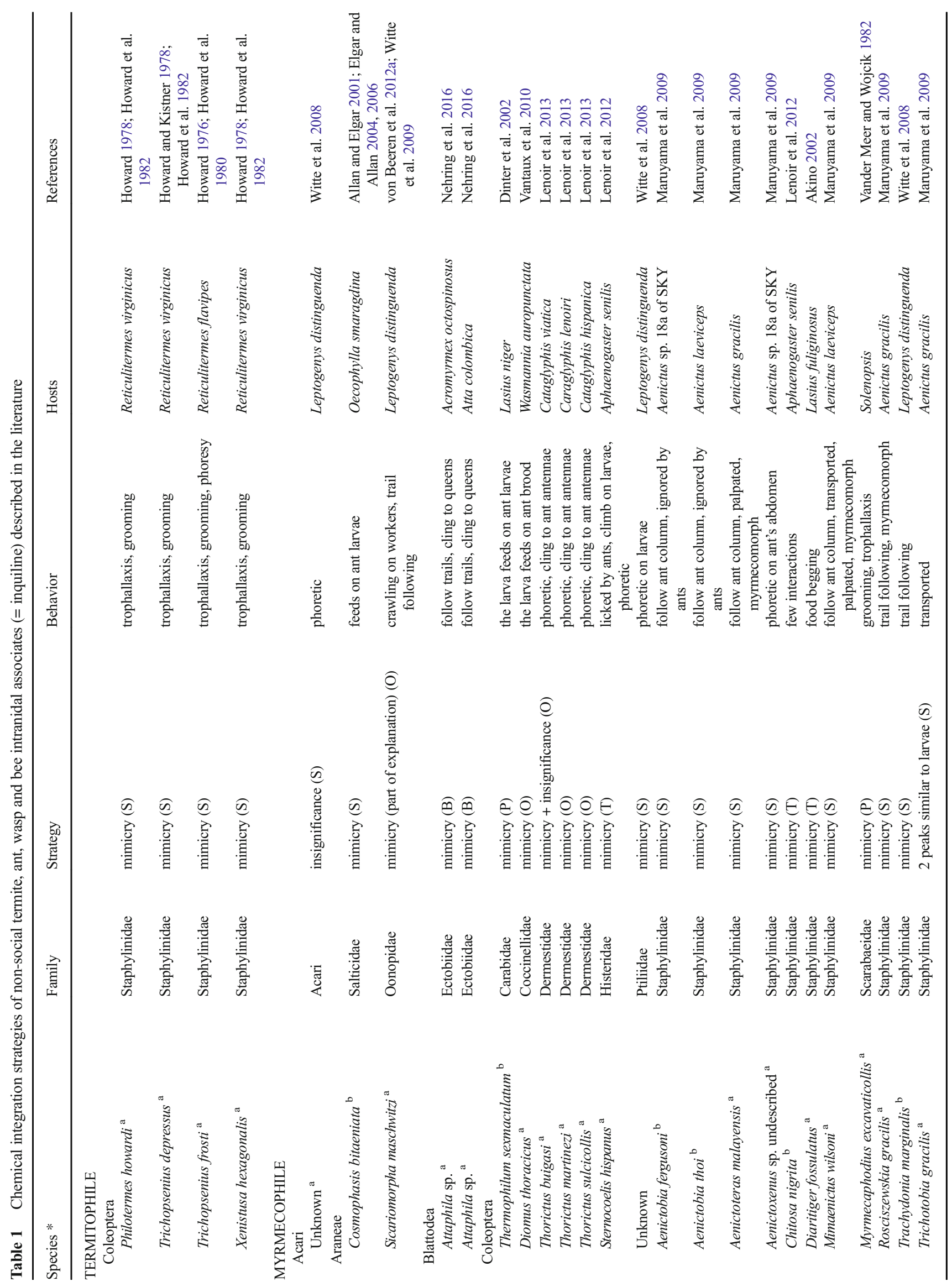




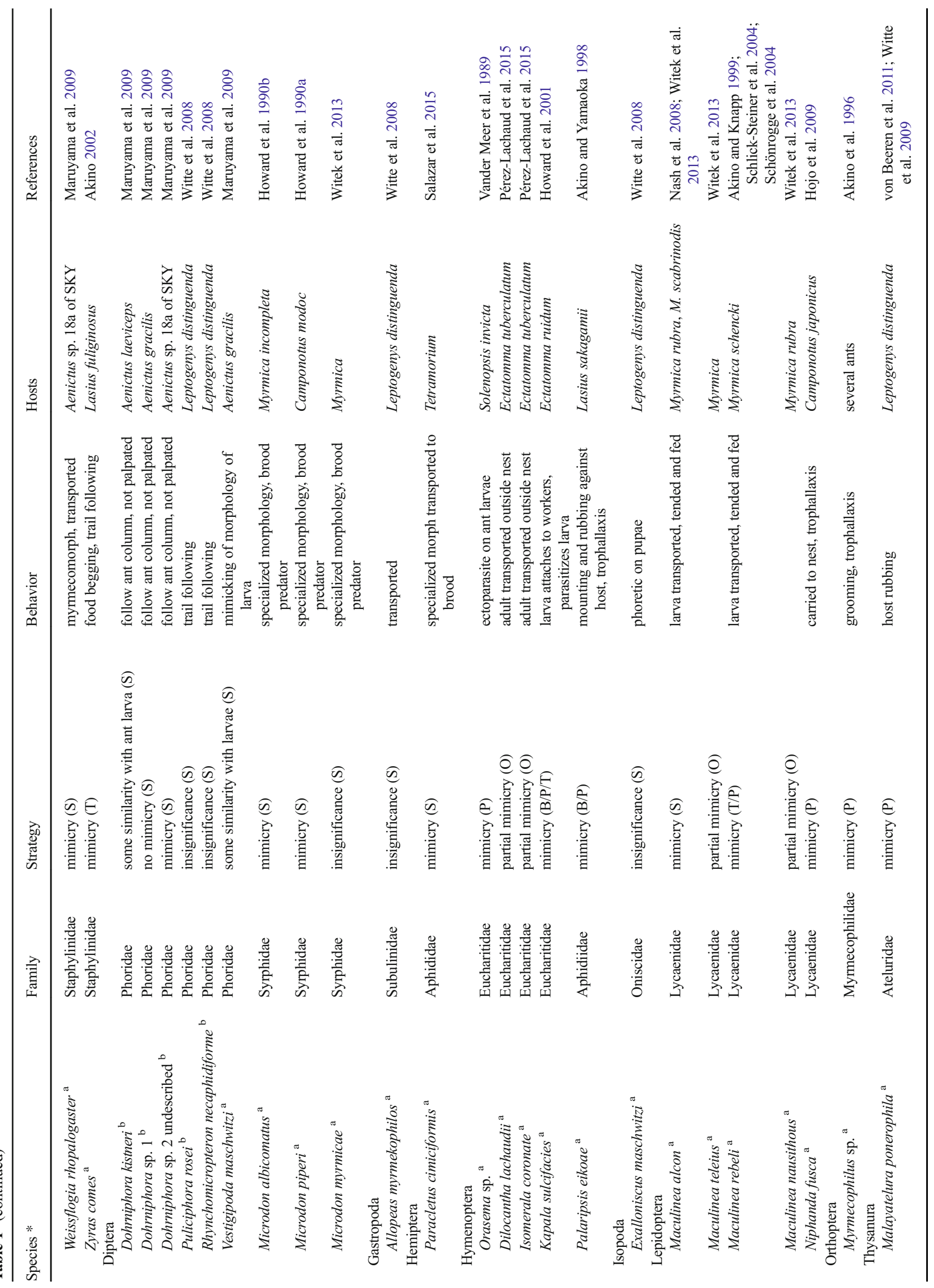




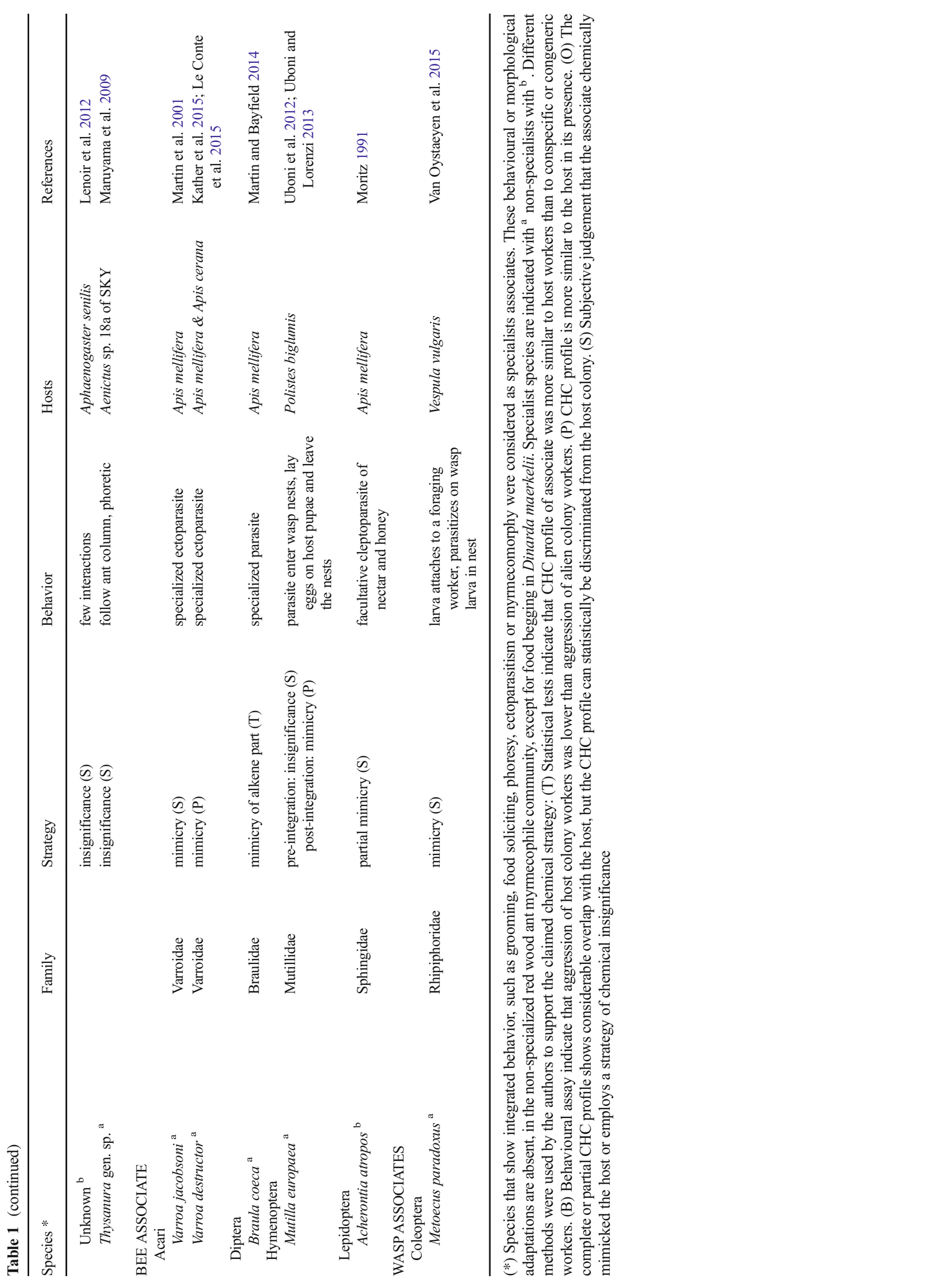




\section{Sample Collection}

Myrmecophiles were collected from three different $F$. rufa populations: R1 (Boeschepe, $50^{\circ} 47^{\prime} 48.48^{\prime \prime} \mathrm{N}, 2^{\circ} 40^{\prime} 31.00^{\prime \prime} \mathrm{E}$ ), R2 (Vladslo, $51^{\circ} 4^{\prime} 17.00^{\prime \prime} \mathrm{N}, 2^{\circ} 55^{\prime} 44.27^{\prime \prime} \mathrm{E}$ ), R3 (WestVleteren, $\left.50^{\circ} 53^{\prime} 7.78^{\prime \prime} \mathrm{N}, 2^{\circ} 41^{\prime} 50.92^{\prime \prime} \mathrm{E}\right)$, six $F$. polyctena populations: O1 (De Haan, 51 $\left.{ }^{\circ} 16^{\prime} 4.72^{\prime \prime} \mathrm{N}, 3^{\circ} 1^{\prime} 18.33^{\prime \prime} \mathrm{E}\right), \mathrm{O} 2$ (Beisbroek, 51 $\left.{ }^{\circ} 10^{\prime} 29.42^{\prime \prime} \mathrm{N}, 3^{\circ} 8^{\prime} 32.14^{\prime \prime} \mathrm{E}\right), \mathrm{O} 3$ (Beernem, $51^{\circ} 7^{\prime} 29.70^{\prime \prime} \mathrm{N}, 3^{\circ} 20^{\prime} 4.37^{\prime \prime} \mathrm{E}$ ), O4 (Aartrijke, $51^{\circ} 8^{\prime} 39.56^{\prime \prime} \mathrm{N}$, $3^{\circ} 4^{\prime} 58.91^{\prime \prime} \mathrm{E}$ ), O5 (Roksem, 51 ${ }^{\circ} 10^{\prime} 27.26^{\prime \prime} \mathrm{N}, 3^{\circ} 3^{\prime} 6.60^{\prime \prime} \mathrm{E}$ ), and O6 (Herentals, $51^{\circ} 11^{\prime} 6.29^{\prime \prime} \mathrm{N}, 4^{\circ} 48^{\prime} 34.99^{\prime \prime} \mathrm{E}$ ) and one F. pratensis population: $\mathrm{P} 1$ (Veltem-Beisem, $50^{\circ} 53^{\prime} 38.78^{\prime \prime} \mathrm{N}$, $4^{\circ} 38^{\prime} 6.74^{\prime \prime E}$ ). In every population, we collected samples from a single polydomous colony. Nest material was taken at different locations in the nest and was gently spread out in a white plastic tray in the field. All myrmecophiles and ants were then collected by using an aspirator, of which the glass reservoir was regularly cleaned with hexane to minimize cross-contamination. An overview of the 18 collected inquiline or intranidal myrmecophiles with some life history traits are given in Table 2. In addition to these 18 RWA inquilines, three RWA myrmecophiles that live extranidally were collected: adults and larvae of the ladybird Coccinella magnifica, (Coccinellidae) (Sloggett et al. 1998) and adults of the leaf beetle Clytra quadripunctata (Chrysomelidae) (the larvae live intranidally) were captured on plants around RWA mounds, whereas the rove beetle Pella humeralis (Staphylinidae) that mostly scavenges in the neighbourhood of ant trails (Donisthorpe 1927), was found at the periphery of a RWA nest. Finally, two facultative myrmecophiles were collected: Porcellio scaber (the common rough woodlouse) and Xantholinus linearis, a rove beetle. In contrast to the myrmecophiles mentioned before, these species are typically not found in close contact with ants, but can occasionally also be found inside RWA mounds (Parmentier et al. 2014). Finally, we collected individuals of the ladybird Coccinella septempunctata, the free-living close relative of C. magnifica. Myrmecophiles and ants were kept together with some nest material and transferred with clean forceps to $2 \mathrm{ml}$ glass vials (Sigma-Aldrich) in the lab for later chemical analysis. Animals were stored in the freezer at $-18{ }^{\circ} \mathrm{C}$ until solvent extraction.

\section{Chemical Analyses}

CHCs from small myrmecophiles were extracted for $10 \mathrm{~min}$ in $30 \mu \mathrm{L}$ of hexane (HPLC grade, Sigma-Aldrich) in $2 \mathrm{ml}$ vials capped with a PTFE septum (Sigma-Aldrich). Large myrmecophiles, such as adults of $C$. quadripunctata, larvae of C. quadripunctata, adults of C. magnifica, larvae of C. magnifica, C. septempunctata, the isopod P. scaber and ant workers were extracted in $200 \mu \mathrm{L}$ of hexane for $10 \mathrm{~min}$. Samples were evaporated to dryness at room temperature in a laminar flow hood and stored at $-18{ }^{\circ} \mathrm{C}$. prior to analysis, samples were redissolved in $6 \mu \mathrm{L}, 30 \mu \mathrm{L}$ or $200 \mu \mathrm{L}$ hexane. These different volumes were based on preliminary runs in which large variation in the total amounts of extracted $\mathrm{CHCs}$ were detected across our different samples. For small myrmecophiles or species with low hydrocarbon concentrations, CHCs of pools of 2 to 20 individuals were extracted per sample. $2 \mu \mathrm{L}$ of each hexane extract was injected into a SHIMADZU QP 2010 ULTRA coupled gas chromatograph/ mass spectrometer (GC/MS-system) equipped with a DB$5 \mathrm{~ms}$ capillary column $(30 \mathrm{~m} \times 0.25 \mathrm{~mm} \times 0.25 \mu \mathrm{m})$. Gas chromatographic conditions were: $1 \mathrm{~min}$ at $70{ }^{\circ} \mathrm{C}$, two temperature ramps from $70{ }^{\circ} \mathrm{C}$ to $150{ }^{\circ} \mathrm{C}$ at $20^{\circ} \mathrm{C} / \mathrm{min}$ and from $150{ }^{\circ} \mathrm{C}$ to $320^{\circ} \mathrm{C}$ at $3{ }^{\circ} \mathrm{C} / \mathrm{min}$, and the final temperature of $320^{\circ} \mathrm{C}$ was held for $15 \mathrm{~min}$. We used helium as the carrier gas at a flow rate of $1 \mathrm{~mL} / \mathrm{min}$, splitless injection, an inlet temperature of $280^{\circ} \mathrm{C}$, and a final pressure of $75 \mathrm{kPa}$. Mass spectrometry was performed with electron impact [EI] at $70 \mathrm{eV}$. In each batch we ran a linear $\mathrm{C} 7$ to $\mathrm{C} 40$ alkane ladder standard (49452-U, Supelco) at two different concentrations $(0.001 \mu \mathrm{g} /$ $\mathrm{mL}$ and $0.01 \mu \mathrm{g} / \mathrm{mL}$ ). Since we earlier verified that the relationship between peak area and concentration was linear on a $\log$-log scale, quantification of all hydrocarbons (total amount produced in ng per individual) was performed using interpolation on a log-log scale, using the peak areas of the closest eluting $n$-alkane of our external alkane ladders for each compound. Retention indices of all compounds were calculated using cubic spline interpolation (Messadi et al. 1990) based on the elution times of the external alkane ladders.

Peaks of CHCs were identified on the basis of expected mass spectrometric fragmentation patterns and retention indices provided by the NIST 2014 retention index database (available online in the NIST Chemistry Webbook, Linstrom and Mallard 2016) or by Pherobase (El-Sayed 2016). Retention indices and diagnostic ions are reported in Supplementary Material 1 . Structure assignment of $n$-alkanes and monomethyl alkanes is straightforward and unambiguous (Carlson et al. 1998; Gerhardt et al. 2016). However, structure assignment of dimethylalkanes is more difficult as two different dimethyl alkanes can produce the same mass spectra (Gerhardt et al. 2016). In accordance with Gerhardt et al. (2016), we only considered dimethyl alkanes with an odd number of methylene groups between the branches, because they are biosynthetically most likely (Carlson et al. 1998). Double bond positions of alkenes of RWA workers were determined by using dimethyldisulfide (DMDS) derivatization of a pooled sample of 10 workers (Carlson et al. 1989). Diagnostic ions of DMDS alkene derivatives are given in Supplementary Material 1,. Unfortunately, we had too little material available to identify alkene double bonds of myrmecophiles using DMDS derivatization. Peak assignments were restricted to CHCs with chain lengths between $n$-C20 and $n$ $\mathrm{C} 40$ and which comprised more than $0.1 \%$ of the estimated 


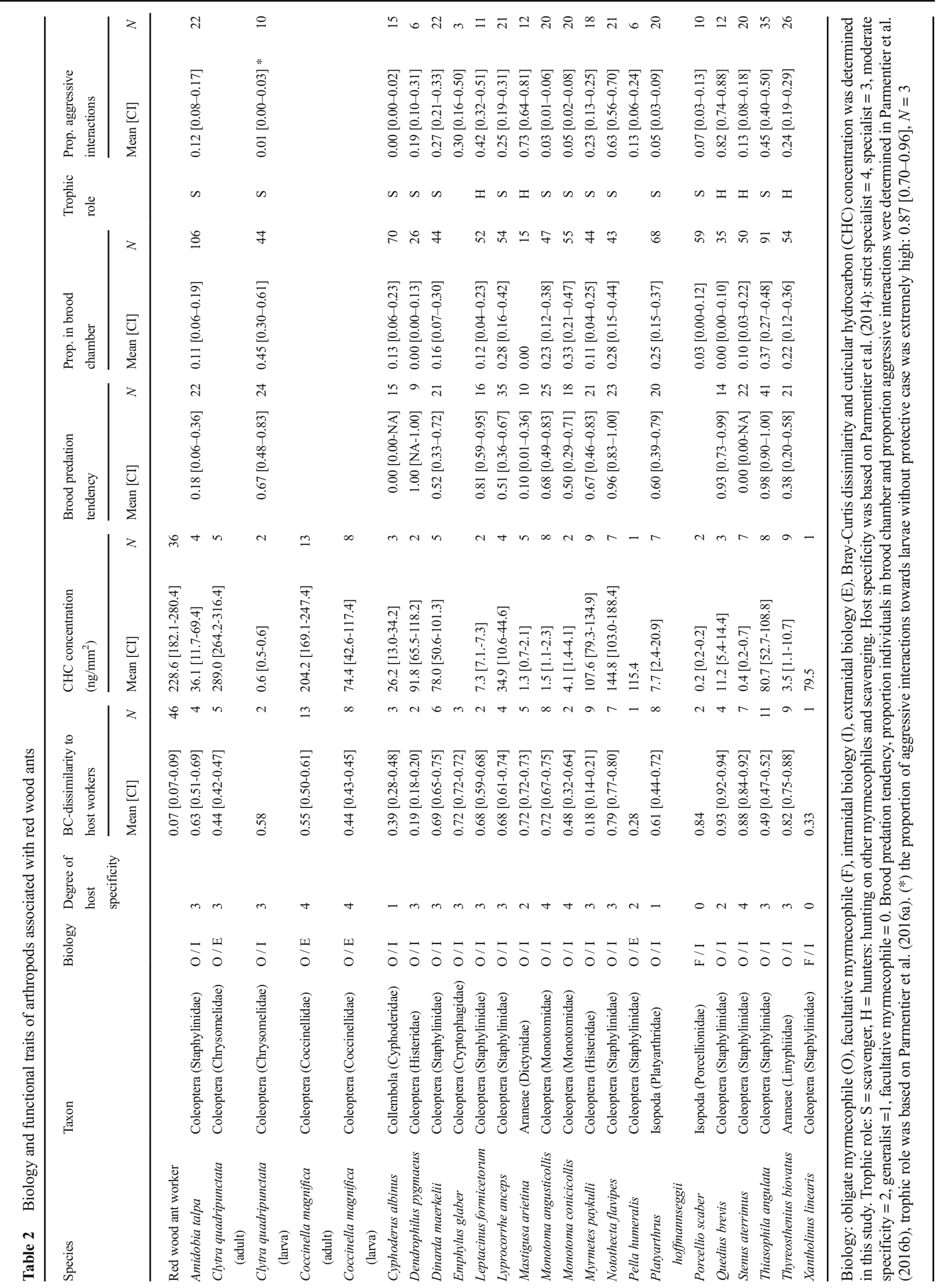


total sample mass of compounds eluting between $n$-C20 and $\mathrm{n}-\mathrm{C} 40$. The identification and quantification of $\mathrm{CHCs}$ with longer chains was impossible because of the limitations of the used column and our GC/MS-system.

This range was chosen based on the fact that there is direct behavioral evidence that $\mathrm{CHCs}$ in this range contain colony-specific and species-specific nestmate recognition cues in both mound-building Formica ants (Martin et al. 2008c) and in Formica ants living in soil nests (Akino et al. 2004b). An important role of these hydrocarbons in nestmate recognition of red wood ants and related mound-building Formica species has also been suggested in other studies (Martin et al. 2008a; Nielsen et al. 1999; Sorvari et al. 2008). Myrmecophiles that mimic their RWA host can, therefore, be expected to have a matching $\mathrm{CHC}$ profile in this range. One study reported that the cuticle of red wood ants also contain some compounds longer than $n$ C40 (Sutton et al. 2013), but it remains unknown, whether any of these have a clear biological function, and we were unable to quantify or identify these compounds due to the analytical limitations mentioned above.

\section{Testing the Nature of the Observed Chemical Integration Strategies}

A priori, we expected that chemical mimicry should translate into a high chemical similarity between hosts and parasites, whereas chemical insignificance should be reflected in low amounts of CHCs. To be able to test which of these chemical integration strategies applied to our study species, we quantified chemical dissimilarity for each myrmecophile individual based on the mean Bray-Curtis dissimilarity to the $\mathrm{CHC}$ profiles of host colony workers, using square-root transformed relative quantities (in $\mathrm{ng}$ ). This transformation was used to down weigh the effect of very large peaks and which was selected due to the fact that it preserves quantitative information and can also deal with zero values. The amount of $\mathrm{CHCs}$ per unit of cuticular surface area ("CHC concentration", in $\mathrm{ng} / \mathrm{mm}^{2}$, i.e. corrected for the variation in body size) was calculated by dividing the estimated absolute $\mathrm{CHC}$ amounts (ng) by the individually estimated cuticular surface area or by the sum of estimated cuticular surface areas in pooled samples. Surface areas were determined using a Wild M3 binocular stereomicroscope with a measuring eyepiece and done by subdividing the bodies of the animals into basic geometric shapes, cf. detailed methodology and data given in Supplementary Material 2.

\section{Chemical Strategy and Host Aggression}

Here we tested the correlation of chemical dissimilarity (Bray-Curtis dissimilarity) and concentration of CHCs
( $\mathrm{ng} / \mathrm{mm}^{2}$ cuticle) with host aggression in order to find general patterns in the chemical integration mechanisms used by the different species studied. The dependent variable "Host aggression" was already determined in Parmentier et al. (2016b). Ant aggression was scored by the proportion of aggressive host ant interactions (acid spraying, chasing, biting, opening mandibles) out of the first 20 interactions towards a myrmecophile in controlled aggression trials. In addition to chemical dissimilarity and concentration of $\mathrm{CHCs}$, we also included other functional traits as independent variables in our model. These functional traits included taxonomic group (family level), host specificity, brood predation tendency, the level of nest integration, trophic role and body size. Host specificity was based on a previous literature study which summarized all known ant hosts of myrmecophiles associated with RWAs (Parmentier et al. 2014). For this study, we categorized the tested myrmecophiles in 4 categories with different degrees of host specificity and assigned a rank: strict specialist $=4$ : only records with RWAs; specialist $=3$ : some records with non RWAs, but RWAs are the main host; moderate specificity $=2$ : records with RWAs, but distribution in non-RWAs probably important as well; generalist $=1$ : myrmecophiles with a broad host spectrum. Brood predation tendency of a myrmecophile species was quantified as the proportion of individuals that preyed on eggs of red wood ant (Parmentier et al. 2016b). The level of nest integration reports the proportion of individuals that preferred densely populated chambers with ant brood to less crowded chambers without brood (Parmentier et al. 2016b). The trophic role was determined by offering different food sources (Parmentier et al. 2016a). Species that fed on ant brood and dead prey were categorized as scavengers. Species that preyed on other myrmecophiles (and also scavenged) were classified as hunters. Body size $\left(\mathrm{mm}^{2}\right)$ was estimated as the total cuticular surface (see above and Supplementary Material 2).

\section{Statistical Analyses}

To visualise the chemical similarities of the complete $\mathrm{CHC}$ profiles, a hierarchical cluster analysis was calculated from the Bray-Curtis dissimilarity matrix of the standardized CHC quantities using the unweighted pair group method (UPGMA) algorithm and the hclust function in R. Apart from the similarity of the total set of hydrocarbons, we examined the pattern of similarity within a subset of different classes of hydrocarbons with separate cluster analyses. These classes included $n$-alkanes, methyl-branched alkanes, dimethyl-branched alkanes and $n$-alkenes. This was done to allow for the fact that ants might use only a subset of the hydrocarbons to recognize nestmates (Martin et al. 2008b; Guerrieri et al. 2009) and that myrmecophiles could 
achieve chemical mimicry merely by matching a part of the total bouquet. Peaks of a particular subset were square root transformed and divided by the total (square root transformed) amount of compound present belonging to that class in the profile. For each myrmecophile species, the significance of the CHC similarity with the host ant workers was determined using a PERMANOVA with the adonis function in $\mathrm{R}$ package vegan $2.3-2$, using the Bray-Curtis dissimilarities between the standardized CHC abundances, and using a maximum of 9999 permutations (less only if there were too few samples to carry out this number of permutations, Table 3). Most myrmecophiles were collected from nests of two or even three RWA host species. To account for possible species-specific chemical adaptations to their RWA host ant species, we incorporated a factor "host species" in the strata argument of the adonis function. This factor grouped RWA workers and myrmecophile individuals in three levels, i.e. samples collected in nests of $F$. rufa, F. polyctena and $F$. pratensis. The strata argument only allowed permutations among samples (myrmecophile and workers) within the levels of this grouping factor. A more detailed grouping of workers and myrmecophiles per nest dramatically reduced the maximum number of permutations which could be carried out per species. Hence, we tested the differences between RWA workers and myrmecophiles across nests of the same RWA host species rather than across individual nests. The sample sizes of these tests are listed in Table 3.

The histerid beetles Myrmetes paykulli and Dendrophilus pygmaeus (Histeridae) had many compounds in common with their hosts, but some compounds were present in trace quantities, i.e. lower than the $0.1 \%$ sample mass threshold or were lacking. In addition, some compounds were lacking or present in trace amounts in some ant samples and were not included in the original dataset. To avoid that the absence of compounds or trace compounds could affect the analysis of these chemically matching species, we focused in a more detailed analysis on the CHCs that were present in all RWA worker samples and histerid beetle samples. To have a maximum number of CHCs shared by all RWA samples and histerid beetle samples, we also included hydrocarbons present in a quantity lower than the $0.1 \%$ of the sample mass. We ran similar cluster analyses on the Bray-Curtis dissimilarity matrix of this CHC dataset shared by the three RWA species, M. paykulli, and D. pygmaeus for the complete CHC profile and different subsets of the $\mathrm{CHC}$ profile ( $n$-alkanes, methyl-branched alkanes, dimethyl-branched alkanes and $n$-alkenes). The Bray-Curtis dissimilarity matrices were again based on square root transformed data divided by the total sample amount of CHCs, shared by histerid beetles and RWAs or the total amount of a subset of shared $\mathrm{CHCs}$ for the subset analyses. Because of the high similarity in the profile of RWA workers and beetles, these myrmecophiles might rely not only on species-specific but also on colony-specific adaptations to the chemical profile of the supporting colony. As a result, differences between workers and either M. paykulli or D. pygmaeus were tested with a PERMANOVA in which we included the factor "host colony" in the strata argument of the adonis function.

For each myrmecophile species, we also compared its CHC concentrations $\left(\mathrm{ng} / \mathrm{mm}^{2}\right.$ ) with the $\mathrm{CHC}$ concentrations $\left(\mathrm{ng} / \mathrm{mm}^{2}\right)$ of RWAs using a Wilcoxon rank sum test with continuity correction.

Finally, the effect of different functional traits, including Bray-Curtis dissimilarity and CHC concentration, on host aggression was assessed with a quasibinomial linear model with logit link function using function glm. Only main effects were considered in the model. The most parsimonious model was selected with an exhaustive search based on the quasi Akaike Information Criterion (qAIC), using R package glmulti. Significance was assessed using Type II likelihood ratio tests with the Anova function in R package car. Extranidal myrmecophiles and Emphylus glaber were not included in this analysis as data for the controlling variables were missing (Table 2). The larva of the leaf beetle $C$. quadripunctata was also not considered as it lives enclosed in a case made of ant nest material and ants do not directly detect the chemical composition of the larvae. The variable "CHC concentration" was transformed by dividing the concentrations by the $\mathrm{CHC}$ concentration of RWAs and by subsequently log 10 transforming these relative $\mathrm{CHC}$ concentrations. Body size was also $\log 10$ transformed. Confidence intervals of the $\mathrm{BC}$ dissimilarity to the host workers and the $\mathrm{CHC}$ concentrations reported in Table 2 were estimated via bootstrapping using package boot. Confidence intervals of the other parameters of Table 2 were taken from earlier studies.

All statistical analyses were done in $\mathrm{R}$ version 3.2.1 ( $\mathrm{R}$ Core Team 2014). $P$-values for analyses where we used multiple repeated tests, i.e. for our PERMANOVA tests and Wilcoxon rank sum tests, were corrected for multiple testing using the Benjamini and Hochberg procedure (Benjamini and Hochberg 1995).

\section{Results}

\section{Characteristics of the Chemical Profile}

In total, 118 different GC-peaks, representing CHCs were attributed across all our samples. Supplementary Material 1 provides an overview of hydrocarbons, whereas Supplementary Material 3 shows the percent composition for each hydrocarbon. Some peaks contained several CHCs that could not be separated under the described GC/MS- 
Table 3 Results of Permanova Tests which Compared Pairwise the Differences in Cuticular Hydrocarbon Composition Between Ants and Myrmecophile Species

\begin{tabular}{|c|c|c|c|c|c|c|}
\hline \multirow[t]{2}{*}{ Species } & \multirow[t]{2}{*}{ Permutations } & \multirow[t]{2}{*}{$N$} & \multicolumn{3}{|l|}{ Host species } & \multirow[t]{2}{*}{$\mathrm{P}$} \\
\hline & & & F. polyctena & F. pratensis & F. rufa & \\
\hline Red wood ant workers & & 46 & 26 & 7 & 13 & \\
\hline Amidobia talpa & 9999 & 4 & 1 & & 3 & $<0.001$ \\
\hline Clytra quadripunctata adult & 8568 & 5 & & & 5 & $<0.001$ \\
\hline Clytra quadripunctata larva & 378 & 2 & & & 2 & 0.004 \\
\hline Coccinella magnifica adult & 9999 & 14 & 8 & 6 & & $<0.001$ \\
\hline Coccinella magnifica larva & 9999 & 8 & 8 & & & $<0.001$ \\
\hline Cyphoderus albinus & 5292 & 3 & 2 & & 1 & $<0.001$ \\
\hline Dendrophilus pygmaeus & 378 & 2 & 2 & & & 0.027 \\
\hline Dinarda maerkelii & 9999 & 6 & 3 & & 3 & $<0.001$ \\
\hline Emphylus glaber & 560 & 3 & & & & 0.003 \\
\hline Leptacinus formicetorum & 378 & 2 & 1 & & 1 & $<0.001$ \\
\hline Lyprocorrhe anceps & 9999 & 4 & 1 & 1 & 2 & $<0.001$ \\
\hline Mastigusa arietina & 9999 & 5 & 5 & & & $<0.001$ \\
\hline Monotoma angusticollis & 9999 & 8 & 6 & 1 & 1 & $<0.001$ \\
\hline Monotoma conicicollis & 378 & 2 & 2 & & & 0.003 \\
\hline Myrmetes paykulli & 9999 & 9 & 5 & 2 & 2 & 0.002 \\
\hline Notothecta flavipes & 9999 & 7 & 4 & & 3 & $<0.001$ \\
\hline Pella humeralis & 27 & 1 & 1 & & & 0.039 \\
\hline Platyarthrus hoffmannseggii & 9999 & 8 & 5 & 1 & 2 & $<0.001$ \\
\hline Porcellio scaber & 378 & 2 & 2 & & & 0.004 \\
\hline Quedius brevis & 9999 & 4 & 1 & & 3 & $<0.001$ \\
\hline Stenus aterrimus & 9999 & 7 & 2 & 2 & 3 & $<0.001$ \\
\hline Thiasophila angulata & 9999 & 11 & 4 & 1 & 6 & $<0.001$ \\
\hline Thyreosthenius biovatus & 9999 & 9 & 5 & 1 & 3 & $<0.001$ \\
\hline Xantholinus linearis & 14 & 1 & & & 1 & 0.071 \\
\hline
\end{tabular}

Number of unique permutations, total number of myrmecophile samples $(\mathrm{N})$ and number of samples associated with each red wood ant host are given. Permutations among workers and samples of a myrmecophile species were only allowed within the same level of host species. Benjamini-Hochberg corrected P-values are given in the last column (P) conditions. Red wood ants (RWAs) possessed most CHC peaks $(F$. rufa $=86, F$. polyctena $=87, F$. pratensis $=82)$ together with the histerid beetles M. paykulli $(N=87)$ and D. pygmaeus $(N=78)$ (Supplementary Material 1 and 3$)$. M. paykulli had 83 out of 87 compounds in common with RWAs and D. pygmaeus 76 out of 78. As expected, the profiles of RWA workers comprised almost uniquely CHCs (e.g. F. polyctena 0.97, CI: 0.97-0.98). Myrmecophiles, however, varied vastly in the proportion of hydrocarbons. That is, while profiles of some of the species consisted mainly of CHCs, akin to the situation for the ant hosts (e.g. proportion of $\mathrm{CHC}$ compounds in M. paykulli: 0.95, CI: 0.93-0.96), for other species nonCHCs almost completely dominated the profile (e.g. proportion of CHC compounds in the rove beetle Quedius brevis: 0.03 , CI: $0.00-0.04)$. The exact nature of these compounds would require further studies, as we did not have sufficient material available to unambiguously identify these compounds. In addition, we cannot exclude that some of these compounds originated from glands rather than from the insect cuticle. Characteristic gas chromatograms of the RWA hosts and associated myrmecophiles are shown in Supplementary Material 1.

\section{Testing the Nature of the Observed Chemical Integration Strategies}

The hierarchical cluster analysis of the standardized CHC quantities separated the RWA workers clearly from most myrmecophiles (Fig. 1). Most RWA workers aggregated with workers of the same nest. Sample sizes of most myrmecophiles were relatively small, but differences in $\mathrm{CHC}$ compositions were generally very large and consistent across samples of the same myrmecophile species. The clear distinction in profiles between myrmecophiles and their host is confirmed by PERMANOVA tests (Table 2), 
which showed highly significant differences in all myrmecophiles except for Pella humeralis $(P=0.07)$, where we had low statistical power due to the fact that only 15 unique permutations were possible for this species. Only the histerid beetles M. paykulli and D. pygmaeus aggregated within the RWA clusters (bold leaves in Fig. 1) and showed high similarity in their chemical profiles with RWAs (Supplementary Material 1 and 3). A similarly high dissimilarity between RWA workers and myrmecophiles was observed in the analyses only focusing on methylbranched alkanes (40 peaks) and dimethyl-branched alkanes (28 peaks) (Supplementary Material Fig. S3-S4). RWA workers also grouped more or less with workers of the same nest in these analyses, and only M. paykulli, D. pygmaeus and some individuals of Cyphoderus albinus and Platyarthrus hoffmannseggii were found in the cluster grouping all RWAs. More myrmecophiles clustered with the red wood ants in the analyses limited to $n$-alkanes (17 peaks) and $n$-alkenes (20 peaks) of the CHC profile (Supplementary Material 4, Fig. S1-S2). These two analyses also gave a poorer distinction between worker profiles of different RWA nests, suggesting that $n$-alkanes and $n$-alkenes have a less promintent role in nestmate discrimination. More detailed cluster analyses focusing on the CHCs that RWA workers and the two histerid beetles had in common (55 peaks) were also performed. The RWA workers tend to cluster in distinct nest-specific profiles. D. pygmaeus and M. paykulli were not found within the cluster of the host nest, although the latter tend to group closer to their host nest than to other RWA nests (Fig. 2). Similar patterns were found for all subsets of the CHC profile (Supplementary Material 4, Fig. S5-S8). Permutation tests for all shared CHCs (55 peaks), shared $n$-alkanes (11 peaks), shared methyl-branched-alkanes (21 peaks), shared dimethyl-branched alkanes (14 peaks), and shared $n$-alkenes (5 peaks) showed that $M$. paykulli $(P<0.005$ in all five tests, permutations $=9999)$ and D. pygmaeus $(P=0.067$ in all five tests, lowest value possible as the max. Number of unique permutations was 15) were chemically different from host nest workers. In spite of their similarity in CHCs, they also elicited a significant aggression response (Table 2).

The estimated $\mathrm{CHC}$ concentration per $\mathrm{mm}^{2}$ body surface varied greatly among all tested arthropods. RWAs were characterized, except for adults of Clytra quadripunctata, by the highest $\mathrm{CHC}$ concentration per $\mathrm{mm}^{2}$ body surface (mean concentration \pm SE: $228.6 \mathrm{ng} /$ $\mathrm{mm}^{2} \pm 25.7$, Table 2). Seventeen out of 21 myrmecophiles (for the ladybird Coccinella magnifica and the leaf beetle C. quadripunctata only the larvae had lower concentrations) had significantly lower $\mathrm{CHC}$ concentration than RWA workers (Supplementary Material 5). Some of this observed interspecific variation in $\mathrm{CHC}$ concentrations could result from the rather crude body surface estimates. The latter, however, could not explain the huge differences observed in ants and some myrmecophiles. Indeed, $10 \mathrm{ob}-$ ligate myrmecophiles (Table 2) had concentrations 10 to 1000 -fold lower than that of RWAs. The lowest concentrations were found in the facultative isopod Porcellio scaber (mean concentration \pm SE: $0.19 \mathrm{ng} / \mathrm{mm}^{2} \pm 0.02$, Table 2). Some species (P. scaber, the rove beetle Stenus aterrimus, the root-feeding beetles Monotoma angusticollis and M. conicicollis, the isopod P. hoffmannseggii, the spider Thyreosthenius biovatus and the springtail C. albinus) with very low concentrations of hydrocarbons per $\mathrm{mm}^{2}$ of cuticle were mostly ignored in aggression trials. However, other species with very low hydrocarbon and nonhydrocarbon concentrations were immediately detected and persecuted (e.g. the spider M. arietina and the beetle Q. brevis). Non-hydrocarbons could have different effects on ants ranging from elevated aggression to repelling or to appeasing (Akino 2008; Stoeffler et al. 2011).

\section{Chemical Strategy and Host Aggression}

Our most parsimonious model contained the factors $\log 10$ (relative $\mathrm{CHC}$ concentration), trophic role, Bray-Curtis dissimilarity and proportion of brood predation. Both $\log 10$ (relative CHC concentration) and trophic role contributed significantly to host aggression. Lower CHC concentrations (LR $\left.\chi^{2}=9.00, P=0.003\right)$ and hunters (LR $\chi^{2}=6.48, P=0.011$ ) provoked less aggression (Fig. 3)a,b. Aggression increased with increasing Bray-Curtis dissimilarity and higher proportion of brood predation, but neither relationship quite reached statistical significance $\left(\right.$ LR $\chi^{2}=3.30, P=0.07 ;$ LR $\chi^{2}=3.10, P=0.08$ ) (Fig. 3)c,d. The spider Mastigusa arietina was an outlier in Fig. 3a, c and d.

\section{Discussion}

The present study sheds light on the chemical integration strategies used by arthropods associated with red wood ants (RWAs). Previously, most arthropods associated with social insects have been found to make use of chemical mimicry to integrate into the nests of their host (claimed for 50 out of 61 species tested, see Table 1). By contrast, results of the present study, which focused on arthropods that had a relatively loose association with RWAs, showed that only two of our study species displayed CHC profiles that were similar to those of their host and that the majority did not match the host's chemical profile at all.

The CHC profiles of the three tested RWA species was highly congruent with those reported in earlier studies (Martin et al. 2008b; Włodarczyk 2011). RWA workers 


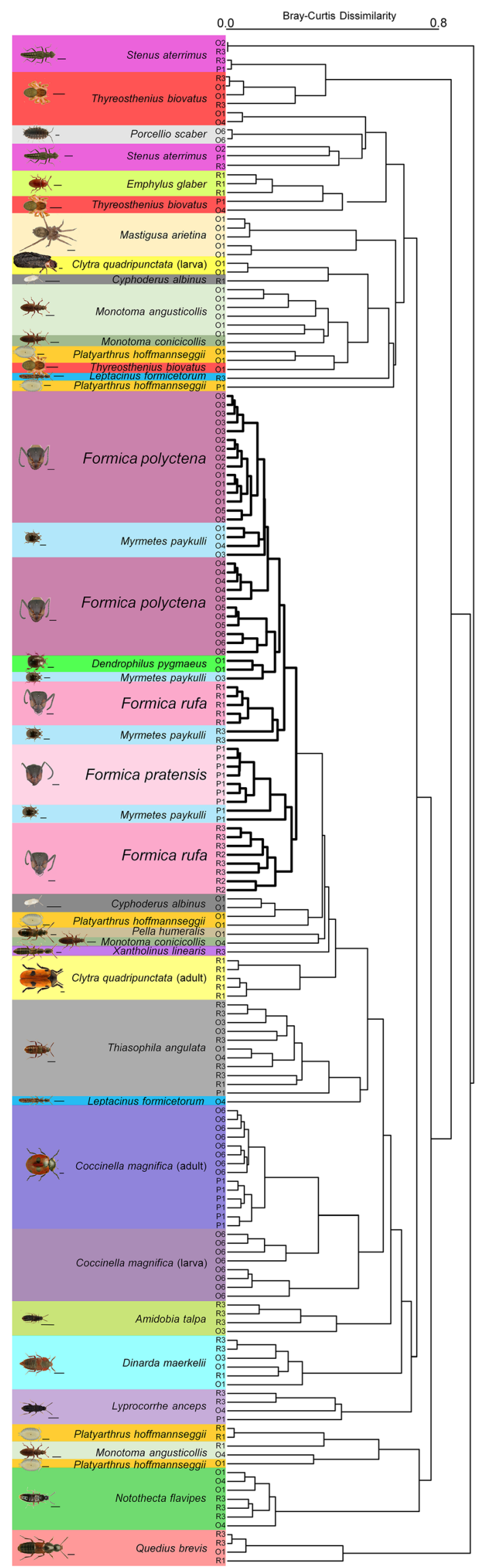

4 Fig. 1 Hierarchical cluster analysis of the cuticular hydrocarbon profiles of red wood ant host species and associated intranidal (inquilines) and extranidal guests. Clustering was conducted with the unweighted pair group method with arithmetic mean and the Bray-Curtis dissimilarity matrix. Scale bars under figures represents a length of $1 \mathrm{~mm}$. Letter code refers to the nest where the sample was collected (O1-6: Formica polyctena nests, P1: Formica pratensis nests, R1-3: Formica rufa nests). Cluster with the thicker leaves groups all red wood ants. Ant figures were adapted from www.AntWeb.org, myrmecophile figures were adapted from pictures kindly provided by Lech Borowiec or by the first author

of the same colony also clustered strongly, based on their similarity in $\mathrm{CHC}$ profiles, in line with their pivotal role in nestmate recognition (Martin et al. 2008a). Martin et al. (2008b) reported that chemical species identity in RWAs is mainly based on dimethyl-alkanes. We found that particularly the dimethyl-branched and methyl-branched alkane fraction of the $\mathrm{CHC}$ profile were more or less colony-specific. The histerid beetles D. pygmaeus and Myrmetes paykulli had almost all components in common with the RWA workers. However, the chemical profiles were distinct from those of their host colony. Chemical mimicry is defined as adaptive resemblance of the $\mathrm{CHC}$ profile of a myrmecophile to their host (von Beeren et al. 2012b). But it is not clear whether the two histerid beetles benefit from the resemblance in CHCs. The beetles were regularly detected and even bitten by the ants (pers. observations TP). Moreover, F. rufa aggression towards M. paykulli individuals found in the same nest was not lower than towards individuals transferred from a F. polyctena colony (Parmentier et al. 2016b). The chemical profile of the 18 other obligate RWA myrmecophile species was clearly different from their RWA host in terms of CHC composition (Supplementary Material 4, Fig. 1). In contrast to RWAs, non-hydrocarbons also contributed significantly to the overall profile of these myrmecophiles. Interestingly, none of these 18 species closely matched the CHC profiles of their RWA hosts (Fig. 1), which was already indicated by aggression transfer experiments between different red wood ant hosts previously performed in 11 species of this group (Parmentier et al. 2016b). However, some myrmecophiles only partially mimic their host (Pérez-Lachaud et al. 2015). The positive trend between increasing chemical distance and host aggression in Fig. $2 \mathrm{C}$ suggest that some mimicry might be better than none. The majority of the myrmecophiles were characterized by significantly lower estimates of $\mathrm{CHC}$ concentrations than their host. We found that lower concentrations of $\mathrm{CHCs}$ were correlated with lower host aggression and therefore, some species may associate with their host via a strategy of chemical insignificance. Ants may discriminate very low $\mathrm{CHC}$ concentrations, as shown in Aphaenogaster senilis which detected alien $\mathrm{CHC}$ 
Fig. 2 Hierarchical cluster analysis of the cuticular hydrocarbons that are shared by three red wood ant host species and two histerid beetles.

Clustering was conducted with the unweighted pair group method with arithmetic mean and the Bray-Curtis dissimilarity matrix. Letter code refers to the nest where the sample was collected (O1-6: Formica polyctena nests, P1: Formica pratensis nest, R1-3: Formica rufa nests)

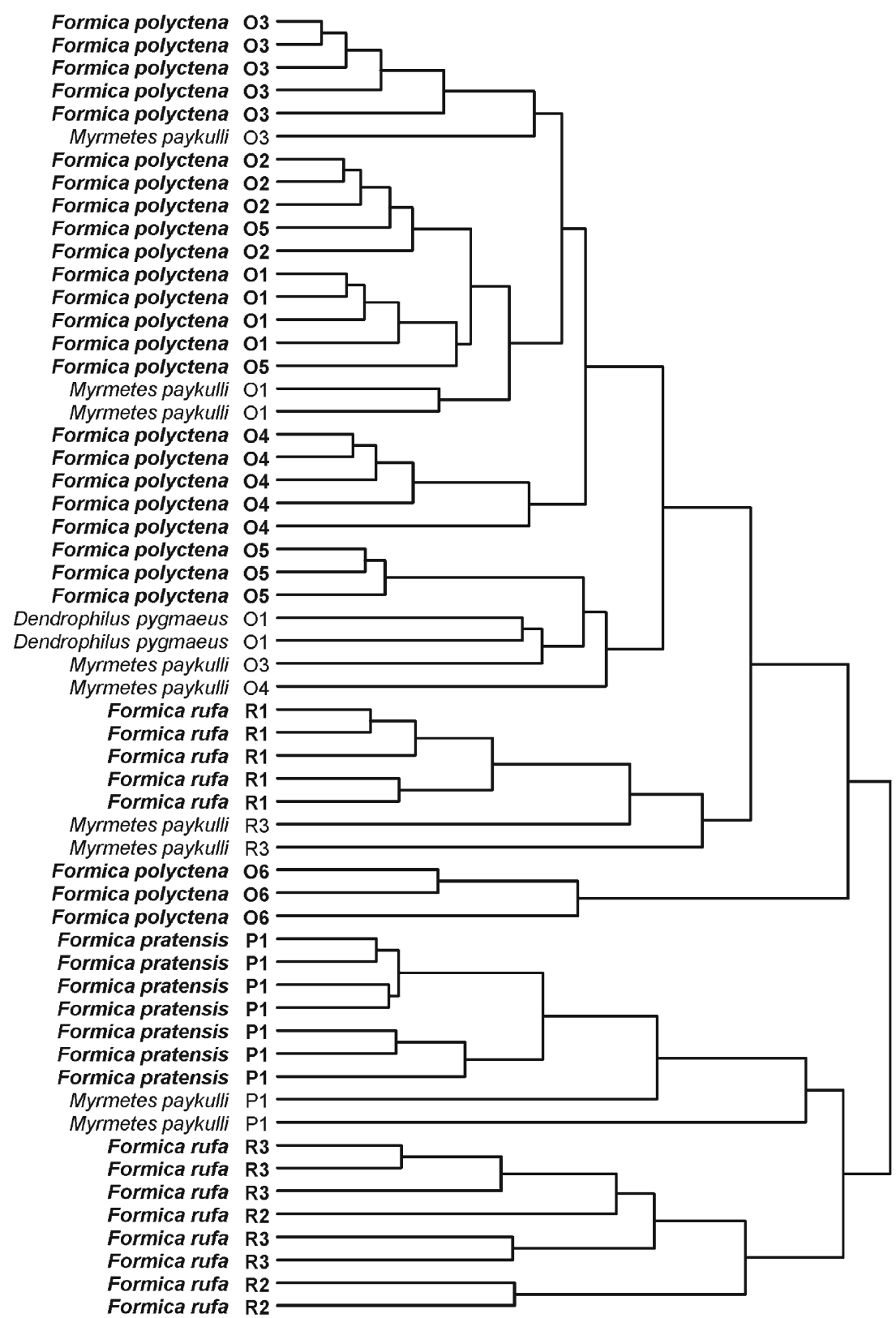

concentrations at a concentration of $0.05 \mathrm{ng} / \mathrm{mm}^{2}$ (Ichinose and Lenoir 2010). This concentration is tenfold lower than the lowest $\mathrm{CHC}$ concentrations measured in the tested myrmecophile community. The effectivity of having low $\mathrm{CHC}$ concentrations as an integration strategy is, therefore, uncertain. But the same study indicated that aggression significantly dropped at lower CHC concentrations, which suggests that low $\mathrm{CHC}$ concentrations might indeed be beneficial. These low CHC concentrations might have an adverse effect. It could affect the sensitivity to desiccation, which is strongly controlled by the concentration of hydrocarbons (Blomquist and Bagnères 2010).
Indeed, we observed that some myrmecophiles, such as $P$. hoffmannseggii and $C$. albinus were very sensitive to drought in the lab. Surprisingly, some species such as the spider $M$. arietina and the beetle $Q$. brevis were heavily aggressed, bitten, and even chased in spite of low CHCconcentrations. High aggression towards these species could be caused by the emission of volatiles, nondetected compounds or by non-hydrocarbon compounds that could elicit strong aggression even in low concentrations. In addition, aggression could be affected by the life style of these myrmecophiles, as we found that species that hunt on other myrmecophiles were more heavily 

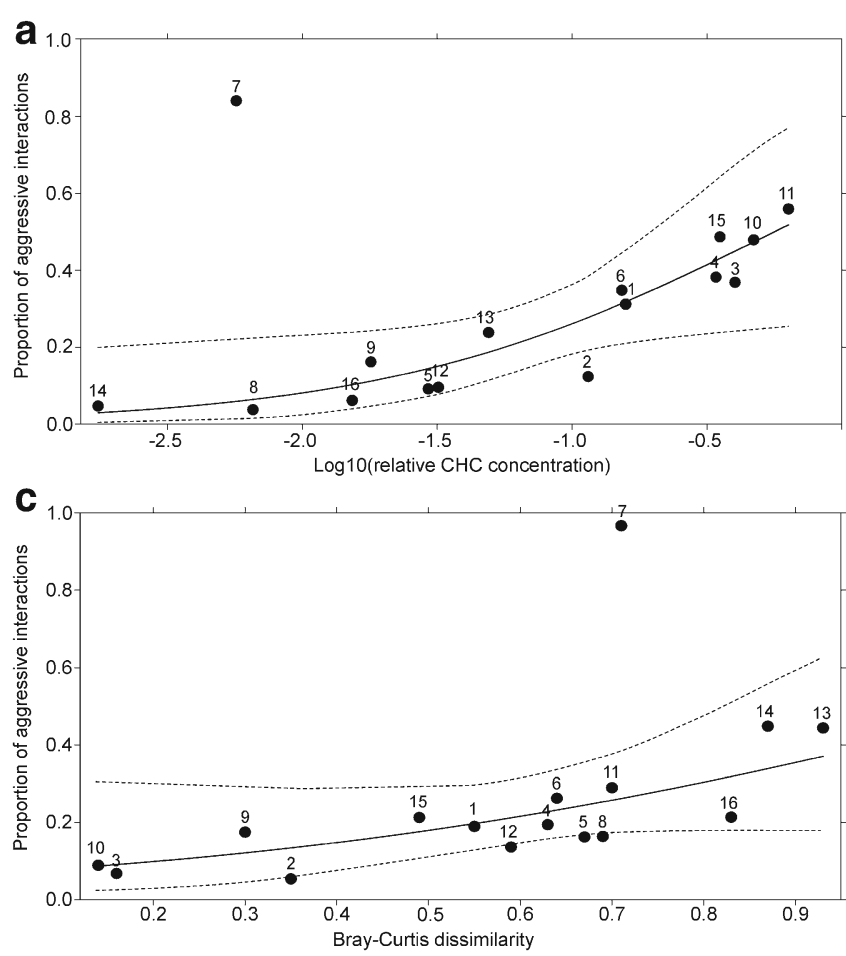

Fig. 3 Residual plots showing the association between host aggression and the four factors retained in the most parsimonious model. Dashed lines indicate upper and lower $95 \%$ confidence limits. a) correlation between $\log 10$ (relative $\mathrm{CHC}$ concentration) and host aggression $(P=0.003)$. b) correlation between trophic role and host aggression $(P=0.011)$. c) correlations between Bray-Curtis dissimilarity and host aggression $(P=0.07)$. d) correlation between proportion of brood

attacked than scavengers. In general, hunters are more active and move faster, which might facilitate their detection. Naked larvae of the leaf beetle Clytra quadripunctata were fiercely attacked, but are normally protected by a case made of excrement and nest material (Donisthorpe 1927) that does not attract the attention of ant workers (Table 1). Rather than matching the profile of the worker caste, myrmecophiles might in principle also target the sexual castes (Hojo et al. 2009) or ant brood (Nash et al. 2008). However, the CHC composition of brood and sexuals only shows minor differences in most social insect species (Elmes et al. 2002; Hojo et al. 2009; Van Oystaeyen et al. 2014) and could not explain the vast differences we observed in the majority of the myrmecophiles. Alternatively, the chemical profile of myrmecophiles might resemble the odor of the nest material. This strategy seems to be employed by an extranidal caterpillar which mimics the odor of its host plant and in this way evades detection by predatory ants (Akino et al. 2004a). Though we cannot rule out such mechanism in our community, we consider this hypothesis unlikely, given that nest material in ant nests gets coated with host-specific cuticular hydrocarbons (Lenoir et al. 2009; Bos et al. 2011). Moreover, the aggression response of ants towards
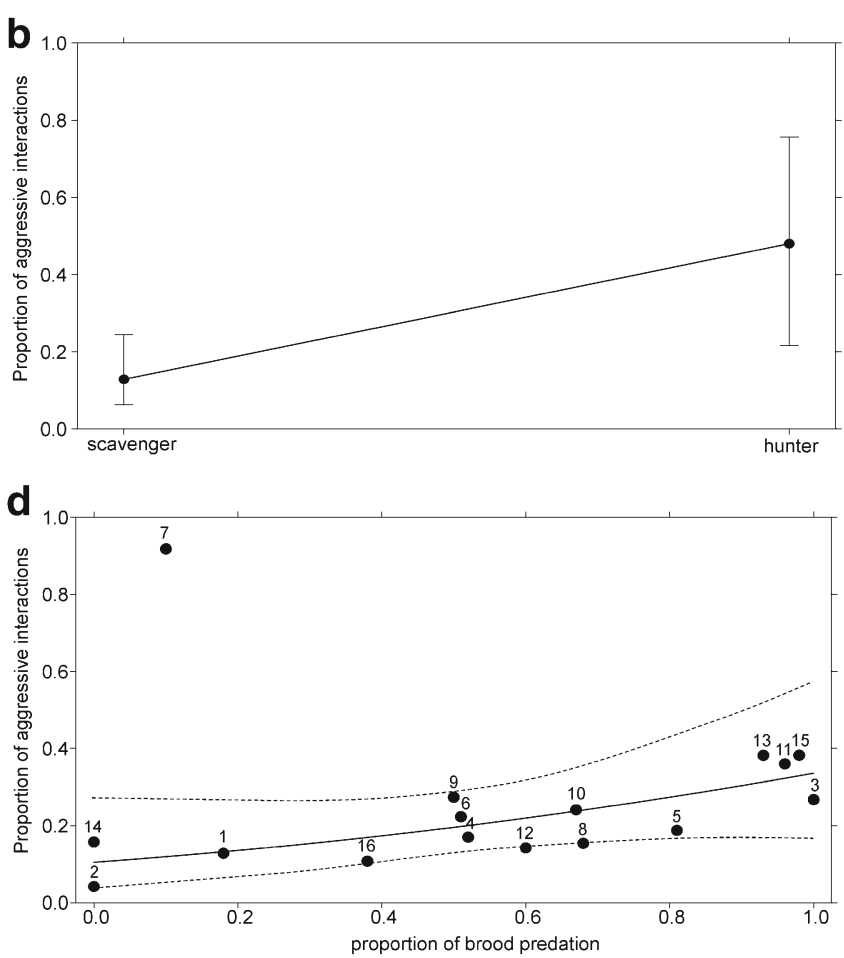

predation and host aggression $(P=0.08)$. Myrmecophile's label: 1 . Amidobia talpa 2. Cyphoderus albinus 3. Dendrophilus pygmaeus 4. Dinarda maerkelii 5. Leptacinus formicetorum 6. Lyprocorrhe anceps 7. Mastigusa arietina 8. Monotoma angusticollis 9. Monotoma conicicollis 10. Myrmetes paykulli 11. Notothecta flavipes 12. Platyarthrus hoffmannseggii 13. Quedius brevis 14. Stenus aterrimus 15. Thiasophila angulata 16. Thyreosthenius biovatus

the myrmecophiles was similar in the presence of nest material (pers. observations TP). In contrast to many parasites that want to mask their identity in the nest (cf. Table 1), mutualists can produce distinct compounds or profiles to attract their partner ant species (Hojo et al. 2014; Richard et al. 2007). Some of the RWA myrmecophiles might provide some indirect mutualistic services (Parmentier et al. 2016a) or they might even mimic the distinct profile of true mutualists to mask their identity as was shown in aphid predators (Liepert and Dettner 1996; Lohman et al. 2006). However, none of the RWA myrmecophiles were treated (grooming, transporting, antennae tapping) as mutualists by the ants (Parmentier et al. 2016b). Therefore, we argue that the tested myrmecophiles do not carry or imitate a distinct "mutualist" chemical profile. Finally, we did not find evidence that RWA myrmecophiles only match a particular structure class of CHCs.

It is surprising that in our study system only 2 out of 18 inquiline arthropods closely matched the $\mathrm{CHC}$ profiles of their host, even though this strategy had been reported for most arthropods living in social insect nests studied up till now. This discrepancy could be explained by the specific structure of a RWA nest of which the aboveground 
part is a dome-shaped mound constructed with organic material, needles, twigs, and other plant material (Gösswald 1989). This haystack-like structure provides many more hiding places for myrmecophiles than typical soil nests (Seifert 2007). Detection of myrmecophiles could further be hampered by the relatively large size of RWAs (Parmentier et al. 2016c). Hence, RWA myrmecophiles might not require chemical mimicry as they could easily run away or hide when detected. However, the underground part of a RWA nest is very similar to a classic underground ant nest, and most of the inquilines used in this study were also found there. Moreover, the majority of RWA inquilines can easily live in chambers with high densities of workers (Parmentier et al. 2016b). Hence, we believe that the aforementioned discrepancy can mainly be explained by a biased focus in the literature on chemical strategies of fairly specialized arthropod inquilines (Table 1). Indeed, the intense interaction of these species with their host is likely only possible by chemically matching the host, whether or not combined with advanced adaptations at the behavioral or morphological level. Although unspecialized species might outnumber the group of specialized associates (; (Wasmann 1894; Kistner 1979; Parmentier et al. 2014), little is known about the chemical integration strategies they employ. The CHC profile of three myrmecophilous beetles that live in the vicinity of the nests of Lasius fuliginosus showed no apparent similarity in CHC composition with their host (Stoeffler et al. 2011). The authors suggested that these extranidal beetles show no disguise as they have plenty of hiding places outside the nest and hardly interact with their host compared to inquilines found inside nests. Our results indicate that unspecialized associates can also survive as inquilines inside densely populated nests without mimicking the $\mathrm{CHC}$ profile, and some of them even prefer the deepest parts of the nest (Table 2). Some might be chemically insignificant but others showed no cuticular chemical disguise. These species might have a similar profile compared to free-living relatives. This is suggested by the slight difference in $\mathrm{CHC}$ that we observed between the obligate myrmecophilous ladybird C. magnifica and its free-living sister species C. septempunctata (Supplementary Material 1 and 3).

Overall, our study suggests that the transition towards a myrmecophilous life history does not require the matching of the host recognition cues. Further studies should compare in-depth the chemical and behavioral strategies of unspecialized myrmecophiles with their free-living relatives. It is likely that unspecialized myrmecophiles might rely on traits or tactics already present in their free-living relatives such as low concentrations of CHCs, tergal glands or specific defensive behavior. These tactics might be sufficient to penetrate and exploit a colony and might be the onset of the evolution towards advanced chemical (special glands, chemical mimicry), morphological, and behavioral strategies needed for a complete assimilation into colony life as seen in most specialized myrmecophiles (Parker 2016).

Acknowledgements This project was supported by Fonds Wetenschappelijk Onderzoek Vlaanderen, grant TP no.11D6414N and Kuleuven (grant TP 253 PDM/16/099). We are grateful for the constructive comments of David Nash and three anonymous referees.

\section{References}

Akino T (2002) Chemical camouflage by myrmecophilous beetles Zyras comes (Coleoptera: Staphylinidae) and Diaritiger fossulatus (Coleoptera: Pselaphidae) to be integrated into the nest of Lasius fuliginosus (hymenoptera: Formicidae). Chemoecology 12:83-89. doi:10.1007/s00049-002-8330-4

Akino T (2008) Chemical strategies to deal with ants : a review of mimicry, camouflage, propaganda, and phytomimesis by ants (Hymenoptera : Formicidae) and other arthropods. Myrmecological News 11:173181

Akino T, Knapp J (1999) Chemical mimicry and host specificity in the butterfly Maculinea rebeli, a social parasite of Myrmica ant colonies. Proc Roy Soc B Biol Sci 266:1419-1426

Akino T, Yamaoka R (1998) Chemical mimicry in the root aphid parasitoid Paralipsis eikoae Yasumatsu (hHymenoptera : Aphidiidae) of the aphid-attending ant Lasius sakagamii. Chemoecology 161:153161

Akino T, Mochizuki R, Morimoto M, Yamaoka R (1996) Chemical camouflage of myrmecophilous cricket Myrmecophilus sp. to be integrated with several ant species. Jpn J Appl Entomol Zool 40:39-46. doi:10.1303/jjaez.40.39

Akino T, Nakamura KI, Wakamura S (2004a) Diet-induced chemical phytomimesis by twig-like caterpillars of Biston robustum Butler (Lepidoptera: Geometridae). Chemoecology 14:165-174. doi:10. 1007/s00049-004-0274-4

Akino T, Yamamura K, Wakamura S, Yamaoka R (2004b) Direct behavioral evidence for hydrocarbons as nestmate recognition cues in Formica japonica (hymenoptera : Formicidae). Appl Entomol Zool 39:381-387. doi:10.1303/aez.2004.381

Allan R, Elgar M (2001) Exploitation of the green tree ant, Oecophylla smaragdina, by the salticid spider Cosmophasis bitaeniata. Aust J Zool 49:129-137

von Beeren C, Schulz S, Hashim R, Witte V (2011) Acquisition of chemical recognition cues facilitates integration into ant societies. BMC Ecol 11:30. doi:10.1186/1472-6785-11-30

von Beeren C, Hashim R, Witte V (2012a) The social integration of a myrmecophilous spider does not depend exclusively on chemical mimicry. J Chem Ecol 38:262-271. doi:10.1007/s10886-0120083-0

von Beeren C, Pohl S, Witte V (2012b) On the use of adaptive resemblance terms in chemical ecology. Psyche 2012. doi:10.1155/2012/ 635761

Benjamini Y, Hochberg Y (1995) Controlling the false discovery rate: a practical and powerful approach to multiple testing. J R Stat Soc B 57:289-300. doi:10.2307/2346101

Blomquist GJ, Bagnères AG (2010). Insect hydrocarbons: biology, biochemistry, and chemical ecology. Cambridge University Press

Bos N, Grinsted L, Holman L (2011) Wax on, wax off : Nest soil facilitates indirect transfer of recognition cues between ant nestmates. PLoS One 6:2-7. doi:10.1371/journal.pone.0019435 
Buschinger A (2009) Social parasitism among ants : a review (Hymenoptera : Formicidae). Myrmecological News 12:219-235

Carlson DA, Roan CS, Yost RA, Hector J (1989) Dimethyl disulfide derivatives of long chain alkenes, alkadienes, and alkatrienes for gas chromatography/mass spectrometry. Anal Chem 61:15641571. doi:10.1021/ac00189a019

Carlson DA, Bernier UR, Sutton BD (1998) Elution patterns from capillary GC for methyl-branched alkanes. J Chem Ecol 24:1845-1865

Cervo R, Dani FR, Cotoneschi C, Scala C, Lotti I, Strassmann JE, Queller DC, Turillazzi S (2008) Why are larvae of the social parasite wasp Polistes sulcifer not removed from the host nest? Behav Ecol Sociobiol 62:1319-1331. doi:10.1007/s00265-008-0560-1

Dekoninck W, Hendrickx F, Grootaert P, Maelfait J (2010) Present conservation status of red wood ants in north-western Belgium : worse than previously, but not a lost cause. Eur J Entomol 107:209-218

Di Giulio A, Maurizi E, Barbero F, Sala M, Fattorini S, Balletto E, Bonelli S (2015) The pied piper: a parasitic beetle's melodies modulate ant behaviours. PLoS One 10:e0130541. doi:10.1371/journal.pone. 0130541

Dinter K, Paarmann W, Peschke K, Arndtab E (2002) Ecological, behavioural and chemical adaptations to ant predation in species of Thermophilum and Graphipterus (Coleoptera: Carabidae) in the Sahara desert. J Arid Environ 50:267-286. doi:10.1006/jare.2001. 0850

Donisthorpe HSJK (1927) The guests of British ants, their habits and lifehistories. George Routledge and Sons, London

Eberhard W (1977) Aggressive chemical mimicry by a bolas spider. Science 198:1173-1175

Elgar M, Allan R (2004) Predatory spider mimics acquire colony-specific cuticular hydrocarbons from their ant model prey. Naturwissenschaften 91:143-147. doi:10.1007/s00114-004-0507-y

Elgar MA, Allan RA (2006) Chemical mimicry of the ant Oecophylla smaragdina by the myrmecophilous spider Cosmophasis bitaeniata : is it colony-specific ? J Ethol:239-246. doi:10.1007/ s10164-005-0188-9

Elmes GW, Akino T, Thomas JA, Clarke RT, Knapp JJ (2002) Interspecific differences in cuticular hydrocarbon profiles of Myrmica ants are sufficiently consistent to explain host specificity by Maculinea (large blue) butterflies. Oecologia 130:525-535. doi: 10.1007/s00442-001-0857-5

El-Sayed AM (2016) The Pherobase: Database of insect pheromones and semiochemicals <http://www.pherobase.com>

Gerhardt H, Betz O, Albert K, Lämmerhofer M (2016) Insect adhesion secretions: similarities and dissimilarities in hydrocarbon profiles of tarsi and corresponding tibiae. J Chem Ecol 42:725-738

Gösswald K (1989) Die Waldameise Band 1 Biologische Grundlagen. Ökologie und Verhalten, Aula-Verlag Wiesbaden

Guerrieri FJ, Nehring V, Jørgensen CG, Nielsen J, Galizia CG, D'Ettorre P (2009) Ants recognize foes and not friends. Proc Roy Soc B 276: 2461-2468. doi:10.1098/rspb.2008.1860

Hojo MK, Wada-katsumata A, Akino T, Yamaguchi S, Ozaki M, Yamaoka R (2009) Chemical disguise as particular caste of host ants in the ant inquiline parasite Niphanda fusca (Lepidoptera : Lycaenidae). Proc Roy Soc B 276:551-558. doi:10.1098/rspb. 2008.1064

Hojo MK, Yamamoto A, Akino T, Tsuji K, Yamaoka R (2014) Ants use partner specific odors to learn to recognize a mutualistic partner. PLoS One 9:4-11

Hölldobler B, Wilson EO (1990) The ants. Harvard University Press Cambridge, Massachusetts

Howard RW (1976) Observations on behavioral interactions between Trichopsenius frosti (Coleoptera: Staphylinidae) and Reticulitermes flavipes (Kollar) (Isoptera: Rhinotermitidae). Sociobiology 2:189192
Howard RW (1978) Proctodeal feeding by termitophilous Staphylinidae associated with Reticulitermes virginicus (Banks). Science 201:541543

Howard RW, Kistner DH (1978) The eggs of Trichopsenius depressus and T. frosti (Coleoptera, Staphylinidae, Trichopseniinae) with a comparison to those of their host termites Reticulitermes vriginicus and $R$. flavipes. Sociobiology 3:99-106

Howard RW, McDaniel CA, Blomquist GJ (1980) Chemical mimicry as an integrating mechanism: Cuticular hydrocarbons of a termitophile and its host. Science 210:431-433

Howard RW, McDaniel CA, Blomquist GJ (1982) Chemical mimicry as an integrating mechanism for three termitophiles associated with Reticulitermes virginicus (Banks). Psyche 89:157-168

Howard RW, Akre RD, Garnett WB (1990a) Chemical mimicry in an obligate predator of carpenter ants (hymenoptera: Formicidae). Ann Entomol Soc Am 83:607-616. doi:10.1093/aesa/83.3.607

Howard RW, Stanley-Samuelson DW, Akre RD (1990b) Biosynthesis and chemical mimicry from the obligate predator Microdon albicomatus and its ant prey, Myrmica incompleta Provancher (hymenoptera: Formicidae). J Kansas Entomol Soc 63:437-443

Howard RW, Pérez-Lachaud G, Lachaud JP (2001) Cuticular hydrocarbons of Kapala sulcifacies (hymenoptera: Eucharitidae) and its host, the ponerine ant Ectatomma ruidum (hymenoptera: Formicidae). Ann Entomol Soc Am 94:707-716. doi:10.1603/0013-8746(2001) 094[0707:CHOKSH]2.0.CO;2

Ichinose K, Lenoir A (2010) Hydrocarbons detection levels in ants. Insect Soc 57:453-455

Joel DM (1988) Mimicry and mutualism in carnivorous pitcher plants (Sarraceniaceae, Nepenthaceae, Cephalotaceae, Bromeliaceae). Biol J Linn Soc 35:185-197. doi:10.1111/j.1095-8312.1988.tb00465.x

Kather R, Drijfhout FP, Shemilt S, Martin SJ (2015) Evidence for passive chemical camouflage in the parasitic mite Varroa destructor. J Chem Ecol 41:178-186. doi:10.1007/s10886-015-0548-z

Kistner DH (1979) Social and evolutionary significance of social insect symbionts. Soc Insects 1:339-411

Kistner DH (1982) The social insects' bestiary. In: social insects. Academic Press, London, pp 1-244

Kronauer DJC, Pierce NE (2011) Myrmecophiles. Curr Biol 21:208-209. doi:10.1016/j.cub.2011.01.050

Le Conte Y, Huang ZY, Roux M, Zeng ZJ, Christidès J-P, Bagnères A-G (2015) Varroa destructor changes its cuticular hydrocarbons to mimic new hosts. Biol Lett 11:20150233-. doi: 10.1098/rsbl.2015. 0233

Lenoir A, D'Ettorre P, Errard C (2001) Chemical ecology and social parasitism in ants. Annu Rev Entomol 46:537-599

Lenoir A, Depickère S, Devers S, Christidès J-P, Detrain C (2009) Hydrocarbons in the ant Lasius niger: from the cuticle to the nest and home range marking. J Chem Ecol 35:913-921. doi:10.1007/ s10886-009-9669-6

Lenoir A, Chalon Q, Carvajal A, Ruel C, Barroso Á, Lackner T, Boulay R (2012) Chemical integration of myrmecophilous guests in Aphaenogaster ant nests. Psyche 2012:1-12. doi:10.1155/2012/ 840860

Lenoir A, Háva J, Hefetz A, Dahbi A, Cerdá X, Boulay R (2013) Chemical integration of Thorictus myrmecophilous beetles into Cataglyphis ant nests. Biochem Syst Ecol 51:335-342. doi:10. 1016/j.bse.2013.10.002

Liepert C, Dettner K (1996) Role of cuticular hydrocarbons of aphid parasitoids in their relationship to aphid-attending ants. J Chem Ecol 22:695-707

Linstrom PJ, Mallard WG (eds) (2016) NIST chemistry webbook, NIST standard reference database number 69, National Institute of Standards and Technology, Gaithersburg, MD, 20899. <http:// webbook.Nist.Gov>

Lohman DJ, Liao Q, Pierce NE (2006) Convergence of chemical mimicry in a guild of aphid predators. Ecol Entom 31:41-51 
Martin SJ, Bayfield J (2014) Is the bee louse Braula coeca (Diptera) using chemical camouflage to survive within honeybee colonies? Chemoecology 24:165-169. doi:10.1007/s00049-014-0158-1

Martin C, Salvy M, Provost E, Bagnères A-G, Roux M, Crauser D, Clèment J-L, Le Conte Y (2001) Variations in chemical mimicry by the ectoparasitic mite Varroa jacobsoni according to the developmental stage of the host honey- bee Apis mellifera. Insect Biochem Mol Biol 31:365-379

Martin SJ, Helanterä H, Drijfhout FP (2008a) Evolution of speciesspecific cuticular hydrocarbon patterns in Formica ants. Biol J Linnean Soc 95:131-140

Martin SJ, Takahashi J-I, Ono M, Drijfhout FP (2008b) Is the social parasite Vespa dybowskii using chemical transparency to get her eggs accepted? J Insect Physiol 54:700-707. doi:10.1016/j. jinsphys.2008.01.010

Martin SJ, Vitikainen E, Helanterä H, Drijfhout FP (2008c) Chemical basis of nest-mate discrimination in the ant Formica exsecta. Proc Roy Soc B 275:1271-1278. doi:10.1098/rspb.2007.1708

Maruyama M, Akino T, Hashim R, Komatsu T (2009) Behavior and cuticular hydrocarbons of myrmecophilous insects (Coleoptera: Staphylinidae; Diptera : Phoridae; Thysanura) associated with Asian Aenictus army ants (Hymenoptera; Formicidae). Sociobiology 54:19-35

Messadi D, Helaimia F, Ali-Mokhnache S, Boumahraz M (1990) Accurate determination of retention indices in programmed temperature gas chromatography. Chromatographia 29:429-434

Moritz RFA (1991) Chemical camouflage of the Death's head hawkmoth (Acherontia atropos L.) in honeybee colonies. Naturwissenschaften 78:179-182

Nash DR, Boomsma JJ (2008) Communication between hosts and social parasites. In: sociobiology of communication: an interdisciplinary perspecftive. Oxford University Press, p 55-80

Nash DR, Als TD, Maile R, Jones GR, Boomsma JJ (2008) A mosaic of chemical coevolution in a large blue butterfly. Science 319:88-90

Nehring V, Dani FR, Calamai L, Turillazzi S, Bohn H, Klass K-D, d'Ettorre P (2016) Chemical disguise of myrmecophilous cockroaches and its implications for understanding nestmate recognition mechanisms in leaf-cutting ants. BMC Ecol 16:35. doi:10.1186/ s12898-016-0089-5

Nielsen J, Boomsma JJ, Oldham NJ, Petersen HC, Morgan ED (1999) Colony-level and season-specific variation in cuticular hydrocarbon profiles of individual workers in the ant Formica truncorum. Insect Soc 46:58-65

Parker J (2016) Myrmecophily in beetles (Coleoptera): evolutionary patterns and biological mechanisms. Myrmecological News 22:65-108

Parmentier T, Dekoninck W, Wenseleers T (2014) A highly diverse microcosm in a hostile world: a review on the associates of red wood ants (Formica rufa group). Insect Soc 61:229-237. doi:10.1007/ s00040-014-0357-3

Parmentier T, Bouillon S, Dekoninck W, Wenseleers T (2016a) Trophic interactions in an ant nest microcosm: a combined experimental and stable isotope $(\delta 13 \mathrm{C} / \delta 15 \mathrm{~N})$ approach. Oikos 125:1182-1192. doi: 10.1111/oik.02991

Parmentier T, Dekoninck W, Wenseleers T (2016b) Do well-integrated species of an inquiline community have a lower brood predation tendency? A test using red wood ant myrmecophiles. BMC Evol Biol 16:12. doi:10.1186/s12862-016-0583-6

Parmentier T, Dekoninck W, Wenseleers T (2016c) Survival of persecuted myrmecophiles in laboratory nests of different ant species can explain patterns of host use in the field (hymenoptera : Formicidae). Myrmecological News 23:71-79

Pérez-Lachaud G, Bartolo-Reyes JC, Quiroa-Montalván CM, CruzLopez L, Lenoir A, Lachaud JP (2015) How to escape from the host nest: imperfect chemical mimicry in eucharitid parasitoids and exploitation of the ants' hygienic behavior. J Insect Physiol 75:63-72. doi:10.1016/j.jinsphys.2015.03.003
R Core Team (2014) R: A language and environment for statistical computing. R Found. Stat. Comput. Vienna Austria 0:\{ISBN\} $3-$ 900051-07-0

Richard FJ, Poulsen M, Drijfhout F, Jones G, Boomsma JJ (2007) Specificity in chemical profiles of workers, brood and mutualistic fungi in Atta, Acromyrmex and Sericomyrmex fungus-growing ants. J Chem Ecol 33:2281-2229

Salazar A, Fürstenau B, Quero C, Pérez-hidalgo N, Carazo P, Font E (2015) Aggressive mimicry coexists with mutualism in an aphid. Proc Natl Acad Sci U S A 112:1101-1106. doi:10.1073/pnas. 1414061112

Schlick-Steiner BC, Steiner FM, Höttinger H, Nikiforov A, Mistrik R, Schafellner C, Baier P, Christian E (2004) A butterfly's chemical key to various ant forts: intersection-odour or aggregate-odour multihost mimicry? Naturwissenschaften 91:209-214. doi:10.1007/ s00114-004-0518-8

Schönrogge K, Wardlaw JC, Peters AJ, Everett S, Thomas JA, Elmes GW (2004) Changes in chemical signature and host specificity from larval retrieval to full social integration in the myrmecophilous butterfly Maculinea rebeli. J Chem Ecol 30:91-107

Seifert B (2007) Die Ameisen Mittel- und Nordeuropas. Tauer: lutra Verlags- und Vertriebsgesellschaft, Görlitz

Sloggett JJ, Wood RA, Majerus M (1998) Adaptations of Coccinella magnifica Redtenbacher, a myrmecophilous coccinellid, to aggression by wood ants (Formica rufa group). I. Adult behavioral adaptation, its ecological context and evolution. J Insect Behav 11:889904. doi:10.1023/A:1020820428820

Sorvari J, Theodora P, Turillazzi S, Hakkarainen H, Sundström L (2008) Food resources, chemical signaling, and nest mate recognition in the ant Formica aquilonia. Behav Ecol 19:441-447. doi:10.1093/ beheco/arm160

Stoeffler M, Tolasch T, Steidle JLM (2011) Three beetles - three concepts. Different defensive strategies of congeneric myrmecophilous beetles. Behav Ecol Sociobiol 65:1605-1613. doi:10.1007/s00265011-1171-9

Sutton PA, Wilde MJ, Martin SJ, Cvačka J, Vrkoslav V, Rowland SJ (2013) Studies of long chain lipids in insects by high temperature gas chromatography and high temperature gas chromatographymass spectrometry. J Chromatogr A 1297:236-240. doi:10.1016/j. chroma.2013.05.006

Thomas J, Knapp JJ, Akino T, Gerty S, Wakamura S, Simcox DJ, Wardlaw JC, Elmes GW (2002) Parasitoid secretions provoke ant warfare. Nature 417:505-506. doi:10.1038/417505a

Uboni A, Lorenzi MC (2013) Poor odors, strength, and persistence give their rewards to Mutilla europaea visiting dangerous wasp nests. J Insect Behav 26:246-252. doi:10.1007/s10905-012-9362-4

Uboni A, Bagnères A-G, Christidès J-P, Lorenzi MC (2012) Cleptoparasites, social parasites and a common host : chemical insignificance for visiting host nests, chemical mimicry for living in. J Insect Physiol 58:1259-1264. doi:10.1016/j.jinsphys.2012.06.013

Van Oystaeyen A, Oliveira RC, Holman L, van Zweden JS, Romero C, Oi CA, D'Ettorre P, Khalesi M, Billen J, Wackers F, Millar JG, Wenseleers T (2014) Conserved class of queen pheromones stops social insect workers from reproducing. Science 343:287-290. doi: 10.1126/science. 1244899

Van Oystaeyen A, van Zweden JS, Huyghe H, Drijfhout F, Bonckaert W, Wenseleers T (2015) Chemical strategies of the beetle Metoecus paradoxus, social parasite of the wasp Vespula vulgaris. J Chem Ecol 41:1137-1147. doi:10.1007/s10886-015-0652-0

Vander Meer RK, Wojcik DP (1982) Chemical mimicry in the myrmecophilous beetle Myrmecaphodius excavaticollis. Science 218:806808

Vander Meer RK, Jouvenaz DP, Wojcik DP (1989) Chemical mimicry in a parasitoid (hymenoptera: Eucharitidae) of fire ants (hymenoptera: Formicidae). J Chem Ecol 15:2247-2261. doi:10.1007/ BF01014113 
Vantaux A, Roux O, Magro A, Ghomsi NT, Gordon RD, Dejean A (2010) Host-specific myrmecophily and myrmecophagy in the tropical coccinellid Diomus thoracicus in French Guiana. Biotropica 42: $622-629$

Wasmann E (1894) Kritisches Verzeichniss der myrmekophilen und termitophilen Arthropoden. F. L. Dames, Berlin

Witek M, Pietro CL, Barbero F, Patricelli D, Sala M, Bossi S, Maffei M, Woyciechowski M, Balletto E, Bonelli S (2013) Interspecific relationships in co-occurring populations of social parasites and their host ants. Biol J Linn Soc 109:699-709. doi:10.1111/bij.12074

Witte V, Leingärtner A, Sabaß L, Hashim R, Foitzik S (2008) Symbiont microcosm in an ant society and the diversity of interspecific interactions. Anim Behav 76:1477-1486. doi:10.1016/j.anbehav.2008.05.010
Witte V, Foitzik S, Hashim R, Maschwitz U, Schulz S (2009) Fine tuning of social integration by two myrmecophiles of the ponerine army ant, Leptogenys distinguenda. J Chem Ecol 35:355-367. doi:10. 1007/s10886-009-9606-8

Włodarczyk T (2011) Recognition of individuals from mixed colony by Formica sanguinea and Formica polyctena ants. J Insect Behav 25: 105-113. doi:10.1007/s10905-011-9280-x

Wyatt TD (2012) Pheromones and animal behavior: chemical signals and signatures, Cambridge University Press

van Zweden JS, d'Ettorre P (2010) Nestmate recognition in social insects and the role of hydrocarbons. In: Insect hydrocarbons biology, biochemistry and chemical ecology. Cambridge University Press, New York, pp 222-243 